\title{
Methylphenidate: use in daily practice
}

- Jacqueline G. Hugtenburg, Judith E. Griekspoor, Ingrid De Boer, Eibert R. Heerdink, Yung Hwo Tso and Antoine C.G. Egberts

Pharm World Sci (2005) 27: 197-201

๑) Springer 2005

J.G. Hugtenburg (correspondence, e-mail: J.G.Hugtenburg@ pharm.uu.nl), J.E. Griekspoor, I. De Boer, E.R. Heerdink,

A.C.G. Egberts: Department of Pharmacoepidemiology and

Pharmacotherapy, Faculty of Pharmaceutical Sciences, Utrecht

University, Utrecht, The Netherlands

Y.H. Tso: Practice for Child and Adolescent Psychiatry,

Amstelveen, The Netherlands

\section{Key words \\ Children \\ Compliance \\ Drug holiday \\ Efficacy \\ Methylphenidate \\ Pharmacy records \\ Side effects}

The Netherlands

\section{Abstract}

Objective: With the aim of getting more insight into compliance of children using methylphenidate, we studied the day-today use of the drug. In addition, the efficacy and side effects of treatment, stopping, switching to other drugs and the use of additional psychoactive drugs in daily practice were studied. Method: On the basis of pharmacy records, the use of methylphenidate by 52 children was studied. Two parameters for compliance were calculated. By means of a questionnaire, parents were asked about their children's compliance with the use of methylphenidate as well as about their experience with treatment.

Main outcome measure: Compliance, use of methylphenidate in weekends and holidays, self-reported efficacy, side effects, stopping and switching to other drugs.

Results: Depending on the parameter calculated, the percentage of children with a good compliance varied from 25 to $47 \%$. About $65 \%$ of the children used less or no methylphenidate in the weekends and holidays. Sixty-five percent of the parents reported to pass over a dose once in a while. According to $61 \%$ of the parents $(n=28)$ the efficacy of methylphenidate was good or very good. Nine (33\%) of 28 children stopped using methylphenidate. Seven children stopped using the drug because of side-effects or lack of efficacy. Seven children switched to other psychoactive drugs. Fifty-seven percent of all children used additional psychoactive drugs.

Conclusion: The percentage of children having a good compliance calculated on the basis of pharmacy records is rathe low. This is partly the result of the decreased use of methylphenidate in the weekends and holidays.

Accepted August 2004

\section{Introduction}

During the last decade the use of methylphenidate sharply increased ${ }^{1-4}$, which resulted in public concern about this phenomenon ${ }^{5}$. Lack of sufficient data on the efficacy and side-effects of methylphenidate in daily practice and uncertainty about long-term effects contributed to this concern.

In general, compliance with the use of drugs is important for the efficacy of treatment. However, non-compliance frequently occurs in different ways. Patients may take their drugs at the wrong time, take a dose too low or too high, or take their drugs more or less frequently than prescribed. Patients may also stop too early, take drug holidays, or continue too long with the treatment ${ }^{6}$. Non-compliance may result in a reduced efficacy of drug treatment or even enhance the risk of side-effects. In addition, non-compliance interferes with the correct assessment of the efficacy of the drug ${ }^{7}$.

Several drug-related factors such as inefficacy and side-effects are known to influence compliance ${ }^{8}$. It has also been shown that compliance decreases with the frequency that drugs have to be taken ${ }^{9,10}$.

Only limited data on compliance with the use of methylphenidate by children are available. A recent review by Swanson addressed studies of compliance with stimulants ${ }^{11}$. The results of a study involving 76 children showed that $26 \%$ of the parents refused stimulant treatment for their children, and $56 \%$ of the children who started with methylphenidate stopped within 10 months $^{12}$. Assessing compliance with methylphenidate by pill counting, Brown et al. reported a return of $25 \%$ of medication ${ }^{13}$.

Because of side-effects such as growth retardation, parents may withhold medication during holidays. A study evaluating parental approaches for their child's ADHD showed that many parents withheld medication at home and during holidays ${ }^{14}$. Precise data on this phenomenon, however, are not available.

The aim of the present study was to gain more insight into children's compliance with the use of methylphenidate, in The Netherlands. For this purpose, compliance was determined by using data from pharmacy records. In addition, parents of children treated with methylphenidate were asked about the use of methylphenidate by their children and their experience with the drug, by means of a questionnaire.

\section{Method}

\section{Setting and study population}

The study was conducted among 52 children aged 4-14 years who were treated by one child psychiatrist practising in the city of Amstelveen (Amsterdam area). Methylphenidate was dispensed to the children by one of the eight community pharmacies in Amstelveen serving about 80,000 patients. Criteria to participate in this study were the use of methylphenidate from 1 January 1999, at least two recorded prescriptions for the drug and the availability of medical data. At the time the study was performed, methylphenidate was available only as an immediate release formulation.

\section{Assessment of compliance and experience with the use of methylphenidate}

Compliance deduced from pharmacy dispensing data For all children, pharmacy dispensing data were collected from December 1996 till January 1999. For subsequent prescriptions, dispensing date and stop date were collected. In case, if the children had started 
using methylphenidate before 1 December 1996, then the medication overview was studied from this date onwards. If children were using methylphenidate from 31 January 2000, a stop date was chosen on the basis of medical data of the psychiatrist. Gender, age and diagnosis were collected from the medical files. Two parameters for compliance, MED-TOTAL and MED-OUT, were calculated. These parameters have previously been described ${ }^{15-17}$. MED-TOTAL is calculated as T/L. T is the sum of the theoretical number of days of drug use of the individual prescriptions. $L$ is the number of days between the first and the last dispensing date of methylphenidate. At a MED-TOTAL of 1, compliance is optimal. At lower and higher values, respectively, too little and too much medication has been dispensed. MED-OUT is calculated as the sum of days without drug/L. By counting the number of days without drug, the medication saved up is taken into account. A value of MED-OUT of 0 indicates no days without drug use. Higher values indicate one or more days without medication.

\section{Compliance and experiences determined via} a questionnaire for parents

In February 2001, a questionnaire on the use of methylphenidate was sent to 46 parents of the children who used methylphenidate. Parents were also asked about the children's experience with the drug. All children involved in the study of compliance based on pharmacy records participated in this study. However, children not living in Amstelveen were excluded, as well as children of parents considered incapable of completing the questionnaire according to the opinion of the psychiatrist. Application of these criteria led to the exclusion of six children.

The questionnaire contained questions about compliance and experience with the drug. Questions concerning compliance were about the dose, and use of the drug in the weekends, holidays less than 2 weeks and summer holidays, as well as questions about passing over the doses and the reasons for that.

Questions concerning experience with the drug were about the efficacy, side-effects, stopping of the drug, switching to other drugs and the use of additional psychoactive drugs. From a list of side-effects parents could indicate which of those occurred.

Data analysis

Data were analysed using the computer programme SPSS 9.0. Descriptive statistics were applied.

\section{Results}

\section{Compliance on the basis of pharmacy records}

Fifty-two children aged 4-14 years were included in the study. Basic characteristics have been listed in Table 1. Many children suffering from diseases other than ADHD were also prescribed methylphenidate. These included autism, anxiety and depression (Table 1). Twenty-one children also used other drugs.

The MED-TOTAL is presented in increments of 0.2 units in Figure 1. Twenty-five percent of the children had a good compliance. Ten percent of the children had a MED-TOTAL higher than 1.1. These

\begin{tabular}{lc} 
Table 1 & $\begin{array}{l}\text { Basic charactistics of children included in } \\
\text { the study of compliance based on phar- } \\
\text { macy records }\end{array}$ \\
\hline Gender $(n=52)$ & Number \\
\hline Boys & 36 \\
Girls & 16 \\
Age & \\
3-6 years & 16 \\
$7-10$ years & 29 \\
11-14 years & 7 \\
Diagnosis according to child psychiatrist & \\
ADHD & 24 \\
Autism & 11 \\
Anxiety and depression & 10 \\
Combination of diseases & 7 \\
\hline
\end{tabular}

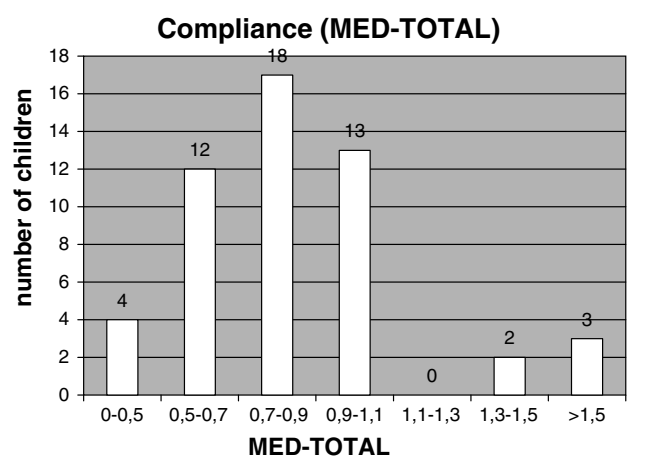

Figure 1 MED-TOTAL for the use of methylphenidate.

MED-TOTAL is lower than 0.9. These children used less than the prescribed amount.

Using 0.2 unit increments, the MED-OUT is presented in Figure 2. A value close to 0 indicates a good compliance. A MED-OUT between 0 and 0.2 was determined for $47 \%$ of the children.

\section{Results of the questionnaire}

Twenty-eight (62\%) questionnaires were returned. Of the 28 children involved, 20 were boys.

Use of methylphenidate and compliance as reported by parents

The dose varied from $10 \mathrm{mg}$ ( 1 child) daily to $40 \mathrm{mg}$ daily ( 1 child). Most children used $20 \mathrm{mg}$ daily. Three, eleven and ten children respectively used methylphenidate once, twice and three times daily.

The use of methylphenidate in the weekends, holidays of 2 weeks and less, and during the summer holidays is presented in Table 2. About 25-30\% did not use methylphenidate in the weekends and about $25 \%$ used less during the weekends and holidays.

Twenty-seven (96\%) parents reported to have discussed changes in drug use with the psychiatrist. The reasons for changing the dose are presented in Table 3. Other reasons for passing over one or more doses were: forgotten to take the medication, no cooperation of the child or one of the parents, waking up late in the weekends and to try out a period without medication. 


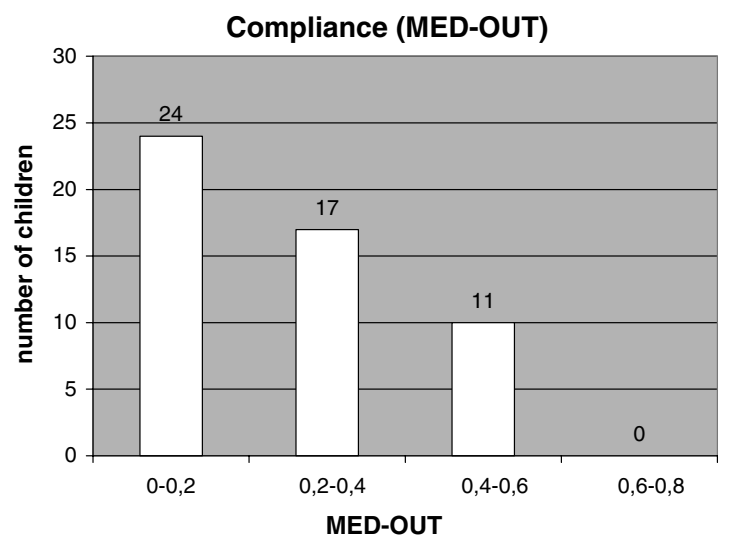

Figure 2 MED-OUT for the use of methylphenidate.

Seven parents (25\%) did not always follow the instructions of the child psychiatrist. The reasons included:

- the occurrence of side-effects; to try out a period without medication; no cooperation of family or practical reasons.

Experience with the drug, stopping use of the drug; switching to other drugs, and use of additional psychoactive drugs according to parents

Nineteen parents $(68 \%)$ considered the efficacy of methylphenidate to be good or very good and six (21\%) thought it to be moderate. Parents of three children $(11 \%)$ were unable to value the effect. In none of the children, methylphenidate had an effect according to the perception of the parents.

Nine $(32 \%)$ of the 28 children had stopped using methylphenidate (Table 4). In seven cases children stopped because of side-effects and/or lack of efficacy (Table 4). One child stopped because treatment with methylphenidate was not necessary anymore. However, seven children who stopped using methylphenidate continued to use other psychoactive drugs, in particular dexamfetamine (five children).

Sixteen (57\%) were prescribed additional psychoactive drugs by the child psychiatrist. In nine cases the presence of other symptoms was the underlying reason. Parents of four children reported that additional drugs were used for the treatment of methylphenidate-induced side-effects. The parents of the 28 children reported a total of 256 side-effects of which sleeplessness, lack of appetite and emotionalism were the most serious ones.

\section{Discussion}

\section{Compliance}

In the present study, two methods were used to investigate compliance with the use of methylphenidate by children. By applying these methods, answers of parents can be used to explain the results obtained by the calculation of compliance on the basis of pharmacy records.

By using pharmacy records, a good compliance with the use of methylphenidate was found in $25-47 \%$ of the children. The level depended on the selected calculation method. The determination of compliance by means of pharmacy records is a simple, quick and cheap method. In particular for drugs which are used daily according to an easy scheme, this method is very useful. However, for the determination of compliance with the use of methylphenidate, there are some disadvantages. The use of this drug in weekends and holidays may be different from that on school days, thus leading to a wrong end date of drug use. In addition, it is not possible to determine whether the drug is taken at the right time. Typing errors of pharmacy staff such as a wrong daily dose may result in wrong end dates, which in turn lead to the calculation of compliance to be too low.

In case if it is known that in certain periods of time the drug use is low, a correction can be applied by taking into account the saved amount of drug. The saved amount may be included in calculating the MED-OUT. Therefore, the percentage of children with a good compliance is higher on the basis of the MED-OUT. By means of calculation of the MED-TOTAL an overuse can be estimated. About $10 \%$ of the children appeared to use more than the prescribed dose.

Data provided by parents showed that about $65 \%$ of the children used no or less methylphenidate in weekends and holidays. Doses were changed or one or more doses were passed over. The lower use in weekends and holiday, however, largely explains the rather low level of compliance found with calculations on the basis of pharmacy records.

Only limited data on compliance with the use of methylphenidate are available in the literature. Brown and co-workers found that about $25 \%$ of prescribed medication was not taken ${ }^{14}$. Although it was not determined which percentage of children was well compliant with prescribed medication, it was concluded that compliance with the use of methylphenidate was quite bad.

\begin{tabular}{llll} 
Table 2 & $\begin{array}{l}\text { Use of methylphenidate during the weekends, during holidays of } \mathbf{2} \text { weeks or shorter and during } \\
\text { summer holidays as compared to school days }(\boldsymbol{n}=28)\end{array}$ \\
\hline Use & $\begin{array}{l}\text { During the weekend } \\
\text { Number of children (\%) }\end{array}$ & $\begin{array}{l}\text { During holiday of } \\
2 \text { weeks or shorter } \\
\text { Number of children (\%) }\end{array}$ & $\begin{array}{l}\text { During summer holidays } \\
\text { Number of children (\%) }\end{array}$ \\
\hline Similar & $11(39)$ & $11(39)$ & $11(39)$ \\
Less & $7(25)$ & $8(29)$ & $7(25)$ \\
No use & $8(29)$ & $7(25)$ & $9(32)$ \\
Unknown & $2(7)$ & $2(7)$ & $1(4)$
\end{tabular}


Table 3 Reasons for adapting the dose and passing over doses $(n=28)$

\begin{tabular}{lcc}
\hline Reason & $\begin{array}{c}\text { Changing the dose } \\
\text { Number of children }\end{array}$ & $\begin{array}{c}\text { Passing over doses } \\
\text { Number of children }\end{array}$ \\
\hline Sufficient effect & 3 & 2 \\
Insufficient effect & 8 & 0 \\
Side-effects & 2 & 1 \\
Combination of reasons & 10 & 2 \\
Other & 5 & 13 \\
\hline
\end{tabular}

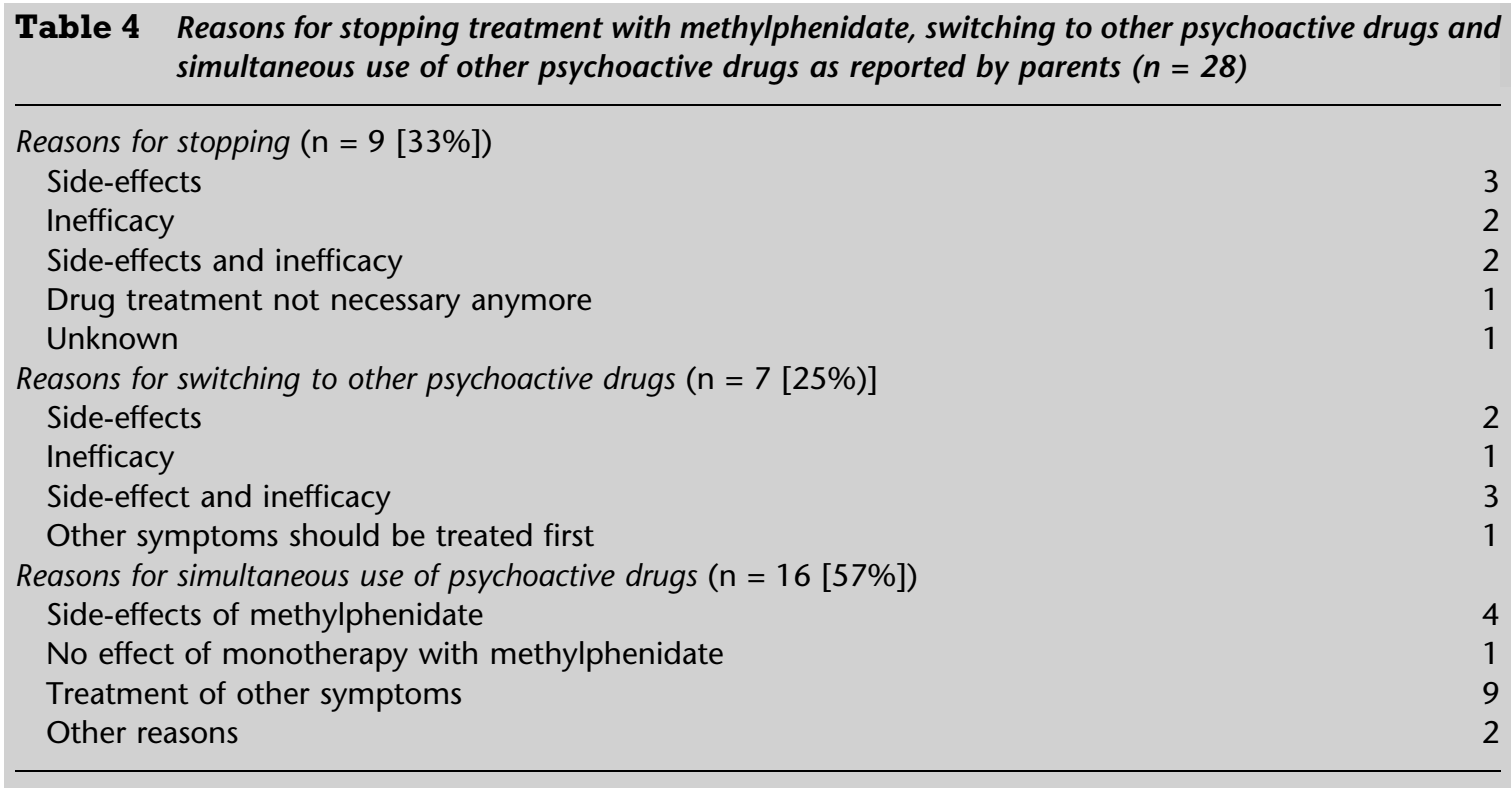

It was not possible to compare pharmacy data with the results of the questionnaire because of anonymisation. In a future study this comparison will be made.

Efficacy and side effects of methylphenidate, stopping and switching

In placebo-controlled trials, methylphenidate is known to improve symptoms of ADHD in $70-80 \%$ of children ${ }^{18}$. The results of the questionnaire have confirmed that methylphenidate is not always effective. To date there is limited knowledge about the reasons for stopping treatment with methylphenidate. It is known that $20-30 \%$ discontinue the use of methylphenidate because of side-effects. Two to four percent stop because of serious side-effects ${ }^{19-21}$. In the present study, parents report the occurrence of side-effects and lack of efficacy to be the most frequent reasons for stopping the drug.

It is remarkable that all parents reported side effects, whereas other studies have shown that only $20-30 \%$ of children experienced side-effects ${ }^{5,20,21}$. However, other studies have also shown that parents of children who use methylphenidate report more side effects than one might expect on the basis of data obtained from clinical trials ${ }^{21}$.

Furthermore, it is noteworthy that children with autism, anxiety and depression are also treated with methylphenidate. The results of a recent study have shown that child psychiatrists and pediatricians pre- scribe methylphenidate for a number of diseases other than ADHD $^{22}$.

\section{Limitations of the study}

The children included in the study were treated by one child psychiatrist. The results may therefore be not representative for a larger population. Although more than $60 \%$ of the parents responded, which is a good score, non-responders may differ from responders with respect to indication, and possibly also compliance. Another limitation may be the result of re-call bias, since $50 \%$ of the children stopped using methylphenidate in the 14 months before they received the questionnaire. Parents may not know the precise answers anymore.

\section{Conclusion}

In the present study we have shown that compliance with the prescribed use of methylphenidate is good in $25-50 \%$ of children. Although the lack of compliance can partly be explained by no or less use of the drug during the weekend, it may be concluded that compliance with the use of methylphenidate can be improved. However, it remains unclear whether improvement of compliance also results in an improvement of the effectiveness of treatment. In this respect more studies of the relationship between compliance and the effects of treatment are required. 


\section{References}

1 Safer DJ, Krager JM. The increased rate of stimulant treatment for hyperactive/inattentive students in secondary schools. Pediatrics 1994; 94: 462-4.

2 Zwi M, Ramchandani P, Joughin $C$. Evidence and belief in ADHD. BMJ 2000; 321: 975-6.

3 Schirm E, Tobi H, Zito JM. Psychotropic medication in children a study from the Netherlands. Pediatrics 2001; 108(2): e25.

4 Berbatis CG, Sunderland VB, Bulsara M. Licit psychostimulant consumption in Australia, 1984-2000: international and jurisdictional comparison. Med J Aust 2002; 177: 539-43.

5 Gezondheidsraad: Diagnostiek en behandeling van ADHD. The Hague: Gezondheidsraad, 2000; publication no. 2000/24.

6 Cramer JA, Mattson RH, Prevey ML, Sceyer RD, Ouellette VL. How often is medication taken as prescribed? A novel assessment technique. JAMA 1989; 261: 3273-7.

7 Epstein LH. The direct effects of compliance on health outcome. Health Psychol 1984; 3: 385-93.

8 Weintraub M, Au W, Lasagna L. Compliance as a determinant of serum digoxin concentration. JAMA 1973; 224: 481-5.

9 Paes AHP, Bakker A, Soe-Agnie CJ. Impact of dosage frequency on patient's compliance. Diabetes Care 1997; 20: 1512-6.

10 Pullar T, Birtwell AD, Wiles PG, Hay A, Freely MP. Use of a pharmacological indicator to investigate compliance with tablets to be taken once, twice or three times daily. Clin Pharmacol Ther 1988; 44, 540-5.

11 Swanson J. Compliance with stimulants for attention-deficit/ hyperactivity disorder. CNS Drugs 2003; 17: 117-31.

12 Firestone P. Factors associated with children's adherence to stimulant medication. Am J Orthopsychiatr 1982; 21: 474-9.

13 Brown RT, Borden KA, Wynne ME, Spunt AL, Clingerman SR. Compliance with pharmacological and cognitive treatments for attention deficit disorder. I Am Acad Child Adolesc Psychiatr 1987; 26: 521-6.

14 Bussing R, Gary FA. Practical guidelines and parental ADHD treatment evaluations: friends or foes? Harvard Rev Psychiatr 2001; 9: 223-33.

15 Steiner JF. The assessment of refill compliance using pharmacy records: methods, validity and applications. J Clin Epidemiol 1997; 50: 105-6.

16 Steiner JF, Koepsell TD, Fihn SD, Inui TS. A general method of compliance assessment using centralized pharmacy records. Med Care 1988; 26: 814-23.

17 Enlud $\mathrm{H}$. Measuring patient compliance in antihypertensive therapy, some methodological aspects. J Clin Hosp Pharm 1982; 7: 43-51.

18 Greenhill LL, Halperin JM, Abikoff H. Stimulant medications. J Am Acad Child Adolesc Psychiatr 1999; 38: 503-12.

19 Barkley RA, McMurray MB, Edelbrock CS, Robbins K. Side effects of methylphenidate in children with attention deficit hyperactivity disorder: a systemic, placebo-controlled evaluation. Pediatrics 1990; 86: 184-92.

20 Efron D, Jarman F, Barker M. Side effect of methylphenidate and dexamphetamine in children with attention deficit hyperactivity disorder: a double-blind, crossover trial. Pediatrics 1997; 100: 662-6.

21 Schachter HM, Pham B, King J, Langford S, Moher D. How efficacious and safe is short-acting methylphenidate for the treatment of attention-deficit disorder in children and adolescents? A meta-analysis. Can Med Ass | 2001; 165: 1475-88.

22 Efron D, Hiscock H, Sewell JR et al. Prescribing psychotropic medication for children by Australian pediatricians and child psychiatrists. Pediatrics 2003; 111: 372-5. 